Original article

\title{
Mothers' management of fever of children in Sabzevar
}

\author{
Shahrbanou Talebi ${ }^{*}$, Hadi Shahrabadi², Ali Vahidi Sabzevar ${ }^{3}$, Somayeh Talebi $^{4}$, Mohammad Siyavoshi $^{5}$
}

(Receive: 4 Jan 2016; Accept: 10 Apr 2016)

\begin{abstract}
Background and Purpose: Fever is one of the most frequent disease symptoms and a common cause of emergency admissions in infants and children. Considering the alarming nature of fever and pivotal role of mothers in the management of this symptom in children, this study aimed to evaluate the ability of fever management among mothers in Sabzevar city, Iran.

Materials and Methods: This cross-sectional study was conducted on 340 mothers with children aged less than 10 years referring to the healthcare centers of Sabzevar city, Iran in 2014. Data were collected using prepared checklists to assess the performance and ability of mothers in the management of fever. Data analysis was performed in SPSS V.20 using descriptive statistics, Mann-Whitney U test, and Kruskal-Wallis test.

Results: In this study, mean score of fever management was $4.65 \pm 1.64$, and $20.9 \%$ of the mothers used antipyretic drugs at the body temperature of $38^{\circ} \mathrm{C}$ to control the fever of children. In addition, $83.7 \%$ of the mothers used antipyretics during the night by waking the children. Our findings were indicative of a significant association between fever management and maternal age $(P=0.048)$, education level $(P=0.002)$, employment status $(P<0.001)$, and referring to community healthcare centers $(P<0.001)$.
\end{abstract}

Conclusion: According to the results of this study, mothers with low education levels required training to promote their performance and conceptions regarding fever in order for the effective management of this common symptom in children.

Keywords: Management, Fever, Children, Mother

\section{Introduction}

Normal human body temperature is $37^{\circ} \mathrm{C}$, and oral body temperature of more than $37.5^{\circ} \mathrm{C}$ is defined as fever $(1,2)$. Fever is a common disease symptom and an immune response against infections $(3,4)$. This condition occurs when the hypothalamic temperature regulation center is affected by endogenous and exogenous phylogenic agents, which leads to increased body temperature (5).

Some of the most frequent fever agents are microbes, microbial toxins, and foreign substances, which enter the body from the external environment. These agents stimulate macrophages and other cells leading to the occurrence of fever (6). Furthermore, viral infections are considered as major causes of febrile illnesses in infants and children. Other common causes of fever include urinary tract infections, connective-vascular tissue diseases, immunization response, malignancies,

\footnotetext{
${ }^{1,{ }^{*}}$ Corresponding author: Students Research Committee, Faculty of Nursing \& Midwifery, Sabzevar University of Medical Sciences, Sabzevar, Iran. Email: shtalebi12@yahoo.com

${ }^{2}$ Department of Exercise Physiology, Office of Education, Sabzevar, Iran

${ }^{3}$ Department of Critical Care Nursing, Faculty of Nursing \& Midwifery, Sabzevar University of Medical Sciences, Sabzevar, Iran

${ }^{4}$ Students Research Committee, Faculty of Health, Sabzevar University of Medical Sciences, Sabzevar, Iran

${ }^{5}$ Department of Medical-Surgical Nursing, Faculty of Nursing \& Midwifery, Sabzevar University of Medical Sciences, Sabzevar, Iran
} 
inflammatory bowel disease, and tissue damage (5).

According to the literature, fever is the primary complaint of $30 \%$ of the patients visited by pediatricians, as well as the most frequent cause of emergency admissions of infants and children $(20 \%)$. The majority of febrile children referred to the emergency departments of healthcare centers are aged between six months and three years old (5).

Since fever is normally considered a medical condition, it is a widespread concern among mothers (4). Previous studies have indicated that parents usually regard fever as a disease rather than a disease symptom (7-9). Fever phobia is a popular concept among some parents whose children appear feverish due to different conditions. This phobia is partly due to the misconception that high fever might lead to the death of infants and young children (5). In one study, $80 \%$ of parents assumed that fever of more than $40-41{ }^{\circ} \mathrm{C}$ could cause severe brain damage in children (2). In this regard, Matzioua et al. (2008) reported that $91 \%$ of parents believed that fever might lead to severe, permanent complications in children, such as encephalitis (46\%), seizure (15\%), and even death (8\%) (8).

In another study, parents were three times more concerned than physicians about possible brain damages associated with high fever and requested medical treatment for fever temperatures below $38^{\circ} \mathrm{C}$ even in the absence of disease symptoms (4). This misconception regarding fever among parents compels them for the readmission of febrile children to healthcare centers, which is time-consuming and imposes unnecessary hospital costs on families (7).

Some researchers have denoted that mothers may become confused and frightened upon the occurrence of fever since they are not able to control the condition and prevent possible complications in children $(10,11)$. In some cases, use of non-standard and toxic drugs to control fever has resulted in the need for emergency readmission of children (7).

According to one study in this regard, only $33 \%$ of parents had good performance in the management of febrile children (12). Furthermore, the findings of Parmar et al. (2001) indicated that only 15\% of parents had a thermometer at home, and only $20 \%$ of these individuals were aware of normal body temperature. Therefore, it was proposed that the parents of febrile children required adequate training in order to enhance their performance in the management of fever (13). In another research conducted by Mohammadi et al. (2010), the majority of parents were unable to use a thermometer correctly in order to measure the fever of children (14).

Fever is considered a foremost disease symptom in children, and mothers play a pivotal role in preserving the health of children. Therefore, adequate knowledge of mothers regarding this condition could affect their attitude and performance in this regard. As proposed by previous research, recognition of effective behavioral factors could remarkably affect the changes in the attitude of individuals (11).

This study aimed to evaluate the ability of mothers in the management of febrile children in Sabzevar city, Iran. It is hoped that the findings of this study lay the ground for the improvement of the quality of healthcare in children and provide guidance for healthcare practitioners in the planning and management of child care.

\section{Materials and Methods}

This descriptive, analytical, cross-sectional study was conducted in Sabzevar city, Iran in 2014. Study population consisted of all the mothers who met the inclusion criteria of the study, and sample size was calculated using the following formula:

$n=t^{2} p q / d^{2}$

In this formula, $\mathrm{t}$ was equal to 1.96 , and $\mathrm{p}$ and q values were determined at $33 \%$ and $67 \%$, respectively based on the studies by Reshadat et al. (2012) and Al- Eissa et al. (2000) (7, 12). In addition, value of $d$ in this study was calculated at 0.05 . Final sample size of this study was estimated at 340 subjects.

In this study, healthcare centers were selected via stratified sampling based on the postal areas of Sabzevar city. Out of six main healthcare centers, four centers were randomly selected based on the residence of the staff of each clinic. Moreover, random sampling was performed based on the 
number of households of families in their medical files that was available in their areas healthcare centers.

The only inclusion criterion of this study was mothers with children aged less than 10 years without chronic diseases.

After explaining the objectives of the study to the participants and obtaining informed consent, prepared questionnaires were completed by the mothers who were willing to participate in the research. Prepared questionnaires consisted of different sections; the first part focused on the demographic characteristics of the mothers, including the age, number of children, education level, employment status, place of residence, and history of infertility, abortion, and stillbirth. The second part of the questionnaire evaluated the ability of the mothers in the fever management of children.

Validity of this questionnaire was determined using the content validity index. In this process, it was confirmed that the questionnaire had been prepared based on valid medical sources. Afterwards, a panel of medical professors, experts, and faculty members of Sabzevar University of Medical Sciences proposed their opinions to be applied in the questionnaire, and the validity of the questionnaire was confirmed after removing ambiguities. Moreover, reliability of the questionnaire was determined at the Cronbach's alpha of 0.82 for 20 participants.

The questionnaire consisted of nine items, with correct responses scored one, and incorrect responses scored zero. Total score of each of the participants was calculated out of nine. In this questionnaire, scores 0-3 were interpreted as poor fever management, scores 4-6 were indicative of average fever management, and scores 7-9 were considered as satisfactory fever management by the mothers.

Data analysis was performed in SPSS V.20, and normal distribution of data was assessed using the Kolmogorov-Smirnov test. In addition, frequency and percentage were determined for demographic variables and fever management scores of the mothers. Correlations between different variables were determined using Mann-Whitney $U$ and Kruskal-Wallis tests. In this study, $\mathrm{P}$ value of less than 0.05 was considered significant.

\section{Results}

In this study, mean score of fever management of children in all the selected healthcare centers was $4.65 \pm 1.64$. As such, $20.9 \%$ of the mothers had poor fever management, $63.5 \%$ had average fever management, and $15.6 \%$ had satisfactory fever management. Other results of this study were indicative of significant correlations between the score of fever management and maternal age $(P=0.048)$, education level $(P=0.002)$, employment status $(P<0.001)$, and healthcare center $(P<0.001)$ (Table 1).

In total, 340 mothers participated in this study. In terms of the medical center, $24 \%$ of the participants were selected from martyr Aldaghi healthcare center, 24\% were selected from Tohid Shahr healthcare center, $32.6 \%$ were selected from the University Square healthcare center, and 19.4\% were selected from Doctor Ghani healthcare center of Sabzevar city.

With regard to age, $24.1 \%$ of the mothers aged less than 25 years, and $11.5 \%$ were over 35 years of age. Moreover, $98.5 \%$ of the mothers were married, while others were divorced or widowed. In terms of employment status, $91.5 \%$ of the mothers were housewives, and $8.5 \%$ were employed.

With respect to the number of children, $44.1 \%$ of the mothers had one child, $40.3 \%$ had two children, and $15.6 \%$ had more than three children. As for the education level, $41.8 \%$ of the mothers had high school diploma, $27.1 \%$ had college education, and $31.1 \%$ were below diploma.

According to the results of this study, $20.9 \%$ of the mothers had a history of abortion, while $3.8 \%$ were reported to have a history of infertility. Moreover, medical history of the children was negative in $65 \%$ of the cases for hospitalization. Measurement of body temperature was carried out by touching the hand of the child in $67.4 \%$ of the mothers, while $24.8 \%$ of the mothers used a thermometer.

According to our findings, fever measurement by the studied mothers was performed using axillary $(20.2 \%)$ and oral thermometers (19.4\%). In 39.2\% 
Table 1. Correlations between fever management scores and demographic characteristics of mothers

\begin{tabular}{|c|c|c|c|}
\hline \multicolumn{2}{|c|}{$\begin{array}{l}\text { Statistical Test } \\
\text { Demographic Variables }\end{array}$} & \multirow{2}{*}{$\begin{array}{l}\text { Statistical Test } \\
\text { Kruskal-Wallis }\end{array}$} & \multirow{2}{*}{$\begin{array}{l}\boldsymbol{P} \text {-value } \\
*_{0.048}\end{array}$} \\
\hline $\begin{array}{l}\text { Age } \\
\text { (year) }\end{array}$ & $\begin{array}{l}\leq 25 \\
35-25 \\
\geq 35\end{array}$ & & \\
\hline Education Level & $\begin{array}{l}\text { Below Diploma } \\
\text { High School Diploma } \\
\text { College Education }\end{array}$ & Kruskal-Wallis & $* 0.002$ \\
\hline $\begin{array}{l}\text { Employment } \\
\text { Status }\end{array}$ & $\begin{array}{l}\text { Employed } \\
\text { Housewife }\end{array}$ & $\begin{array}{c}\text { Mann-Whitney } \\
\text { U }\end{array}$ & $*<0.001$ \\
\hline $\begin{array}{l}\text { Number of } \\
\text { Children }\end{array}$ & $\begin{array}{c}1 \\
2 \\
3 \\
\geq 4 \\
\end{array}$ & Kruskal-Wallis & 0.107 \\
\hline Marital Status & $\begin{array}{c}\text { Married } \\
\text { Divorced } \\
\text { Widowed }\end{array}$ & Kruskal-Wallis & 0.638 \\
\hline Health care Center & $\begin{array}{c}\text { Martyr Aldaghi health } \\
\text { care center } \\
\text { Tohid Shahr healthcare } \\
\text { center University Square } \\
\text { health care center } \\
\text { Dr. Ghani healthcare } \\
\text { center }\end{array}$ & Kruskal-Wallis & $*<0.001$ \\
\hline $\begin{array}{l}\text { History of } \\
\text { Hospitalization }\end{array}$ & $\begin{array}{l}\text { Yes } \\
\text { No }\end{array}$ & $\begin{array}{c}\text { Mann-Whitney } \\
\text { U }\end{array}$ & 0.344 \\
\hline $\begin{array}{l}\text { History of } \\
\text { Infertility }\end{array}$ & $\begin{array}{l}\text { Yes } \\
\text { No }\end{array}$ & $\begin{array}{c}\text { Mann-Whitney } \\
\text { U }\end{array}$ & 0.395 \\
\hline $\begin{array}{l}\text { History of } \\
\text { Abortion }\end{array}$ & $\begin{array}{l}\text { Yes } \\
\text { No }\end{array}$ & $\begin{array}{c}\text { Mann-Whitney } \\
\text { U }\end{array}$ & 0.837 \\
\hline
\end{tabular}

*Significant association between fever management scores and demographic characteristics of mothers $(P<0.05)$

of the cases, mothers measured the body temperature of the child in less than an hour since the onset of fever. Moreover, $41.1 \%$ of the mothers asked for the help of other family members to reduce the body temperature of the child, and $55 \%$ attempted to alleviate the fever independently due to former experience.

With regard to the proceedings of the mothers to lower the body temperature of the child, $63.5 \%$ used antipyretic drugs, $20.2 \%$ used a wet sponge, $15.5 \%$ referred to a physician, and $0.8 \%$ used herbal remedies. It is noteworthy that the majority of these mothers used Violets and Manna.

$61.9 \%$ had no information regarding the proper fever temperature for the use of medicinal herbs. Furthermore, garden violet antipyretics were used by $20.9 \%$ of the mothers at fever temperatures above $38^{\circ} \mathrm{C}$, while $17.1 \%$ used these compounds at fever temperatures above $37^{\circ} \mathrm{C}$. As for other pharmaceutical agents for the alleviation of fever, the majority of the studied mothers used acetaminophen (95.3\%). On the same note, 59.7\% and $29.5 \%$ of the mothers used antipyretics every four and six hours, respectively.

According to the results of this study, $83.7 \%$ of the mothers woke their febrile child for antipyretic administration. Among the mothers who applied a wet sponge to reduce body temperature, $37.2 \%$ used lukewarm water, $22.5 \%$ used cold water, and $20.2 \%$ used salted water. It should be noted that use of wet sponges is one of the first steps to alleviate fever.

With respect to the information sources of the mothers about fever, $57.3 \%$ of our participants consulted a physician or referred to a healthcare center, $27.1 \%$ received advice from friends or family members, and only $10.9 \%$ of the mothers mentioned the media (e.g., television) as their main source of information.

Upon the occurrence of fever in the child, $59.7 \%$ of the mothers referred to a pediatrician, while $34.8 \%$ and $4.7 \%$ referred to a general practitioner or emergency departments, respectively.

\section{Discussion}

According to the results of the present study, mean score of fever management in the mothers was at an average level. In one research, Al- Eissa et al. (2000) reported that only $33 \%$ of the studied parents had satisfactory performance in terms of fever control in children (12). Moreover, the findings of Kim et al. (2008) indicated that many of the studied parents who referred a febrile child to a physician had poor knowledge of fever (15). In this regard, Crocetti et al. (2001) stated that Latin parents had numerous misconceptions towards fever control, some of which were found to deteriorate the condition of the child (16). Based on the aforementioned findings, it is suggested that parents receive adequate training to reduce fever phobia and enhance their knowledge regarding the proper use of antipyretics for children (15). This could enable parents to manage the fever of children effectively.

According to the results of the current study, there was a significant correlation between the mean score of fever management and education level of the 
mother, so that mothers with higher education levels obtained higher fever management scores. Similarly, the findings of Talebian et al. (2009) indicated that with higher education levels, knowledge and attitude of parents toward fever improved remarkably (17). Furthermore, several studies evaluating the performance of mothers in the control of paroxysm associated with fever have shown that higher education of mothers could significantly enhance their performance in this regard (11).

Findings of the present study were indicative of a significant correlation between maternal age and proper fever management; as such, performance of elder mothers was less satisfactory in the effective fever control of children. In their study, Matzioua et al. (2008) reported that mothers aged above 30 years used antipyretics incorrectly to alleviate fever, which is consistent with the results of the present study. (8). This could be due to the fact that younger mothers tend to have higher education levels and use modern approaches to reduce body temperature, while elder mothers resort to traditional remedies in this regard.

As is known, the majority of mothers measure the body temperature of children by touching their skin, which has been shown to be an inaccurate method of fever measurement highly prone to errors. Among the participants of the current study, only $24.8 \%$ used a thermometer to measure fever, and axillary and oral thermometers were reported to be the most common devices used for the body temperature measurement of children.

In another research, Parmar et al. (2001) reported that only $15 \%$ of parents had a thermometer at home (13), which is in line with our findings. On the other hand, the findings of Desnous et al. (2011) indicated that the majority of the studied mothers measured the body temperature of the child using a rectal thermometer, their results also showed that some mothers use axillary thermometers, and a few cases used forehead and axillary thermometers simultaneously (18). According to the results of another study, Greek mothers preferred axillary thermometers to rectal thermometers for measuring the body temperature of children despite the fact that rectal thermometers are a more valid recommendation by Greek physicians (8).

According to the results of the present study, the most frequent proceeding of the mothers to reduce the fever of children was antipyretic administration, followed by foot bath, referring to a physician, and use of medicinal herbs. In another study, Desnous et al. (2011) reported that upon the occurrence of fever, parents immediately used antipyretics for children, which was consistent with the findings of the current study (18). On the other hand, the results of the study by Talebian et al. (2009) indicated that $86.8 \%$ of mothers took no action before referring the febrile child to the hospital, which was inconsistent with our findings (17). In this regard, the surprising results of another research revealed that $25 \%$ of Greek mothers covered children with more clothes upon the occurrence of fever (8).

In case of fever, the most effective measures to improve health by lowering the body temperature include foot bath with lukewarm water (without additional compounds), taking off extra clothes, adequate liquid intake to stimulate hydration, and preserving a moderate temperature in the environment. As for the control of fever and reducing the body temperature of the child, use of antipyretics at proper doses has been confirmed as an effectual method (4).

According to the findings of the present study, $61.9 \%$ of the mothers had poor knowledge regarding the proper dose of antipyretics for different fever temperatures. This was in line with the results obtained by Talebian et al. (2009) and Cinar et al. (2014) $(17,19)$. Moreover, the study by Parmar et al. (2001) demonstrated that only $20 \%$ of parents were aware of normal body temperature (13).

In the present research, $20.9 \%$ of the mothers used antipyretics at fever temperatures above $38^{\circ} \mathrm{C}$, and $17.1 \%$ used these drugs at fever temperatures above $37^{\circ} \mathrm{C}$. This finding was consistent with the results of another study by Impicciatore et al. (1998) (3).

According to the results of the current study, acetaminophen was the most common antipyretic drug used to control fever in children. In another research by Kilmon (1987), 93\% of parents were reported to use chemical agents, such as acetaminophen (87\%) and aspirin $(8 \%)$, for the management of febrile children 
(20). Acetaminophen is the first-line therapeutic drug in the treatment of febrile illnesses since it is absorbed completely in the gastrointestinal tract. In addition, acetaminophen could alleviate fever within 30 minutes to one hour after administration, with the maximum effect manifesting three hours after use. On average, the antipyretic effect of this chemical drug could last for 3-6 hours (21).

Inappropriate use of antipyretics has been shown to result in drowsiness and drug poisoning (7). In the current study, only $4.7 \%$ of the mothers used ibuprofen to reduce the body temperature of febrile children. Ibuprofen is a non-steroidal, antiinflammatory chemical drug, which is absorbed easily through the gastrointestinal tract with the maximum volume of plasma within 1-2 hours after administration. Among the most common side effects of this painkiller are digestive disorders, such as vomiting, diarrhea, and gastrointestinal bleeding (22).

In the research by Noori et al. (2007), ibuprofen was observed to be more effective in the reduction of fever and maintaining low body temperature compared to acetaminophen. In children aged more than six months, use of ibuprofen is recommended by physicians in cases where acetaminophen is not able to reduce fever (22).

In the present study, none of the mothers used aspirin to alleviate the fever of children. Some researchers believe that aspirin should not be used for viral infections due to the associated risk of different syndromes in infants and children (3).

Apart from the use of chemical drugs, many healthcare experts recommend physical treatments for the reduction of fever in children, the most effective of which is foot bath (3). According to the findings of the current research, the most common method to reduce the body temperature of children was foot bath with lukewarm (37.2\%), cold (22.5\%), and salted water (20.2\%). In the study by Kilmon (1987), parents used foot bath with cold water in $36 \%$ of the cases and lukewarm water in $18 \%$ of the cases (20), while in the research by Mohammadi et al. (2010), 87\% of mothers used cool water for the foot bath of febrile children (14). However, the results of the aforementioned studies were inconsistent with our findings.

The World Health Organization (WHO) has prohibited the use of cold water (lowering body temperature and causing body shake) and alcohol (induction of hypoglycemia, brain damage, and risk of poisoning) in foot bath for the control of fever (3).

In the present study, $18.7 \%$ of the mothers used medicinal herbs to reduce the fever of children, the most common of which were manna and viola. In the study by Reshadat et al. (2012), Sisymbrium irio was the most common medicinal herb used to alleviate fever in children. Use of herbal remedies depends on the geographical region and cultural background of different populations. It is also noteworthy that credible sources have confirmed the efficacy of sufficient liquid intake in fever management through stimulating body hydration (7).

Sensitivity and concern of parents compels them to wake their child upon the detection of fever. According to the findings of the current study, $83.7 \%$ of the mothers woke their child as soon as the occurrence of fever. In other studies by Sarrell et al. (2002), Sajadi Hazaveh et al. (2011), and Desnous et al. (2011), this rate was reported to be $65.5 \%, 42 \%$, and $33.2 \%$, respectively $(4,11,18)$.

Essential knowledge of mothers about fever in children is provided by physicians and healthcare centers $(57.3 \%)$, followed by friends and relatives (27.1\%). According to the results obtained by Kilmon (1987), $72.2 \%$ of mothers received information on fever management using educational packages, $6.2 \%$ from friends and relatives, $14.4 \%$ from healthcare centers, and $7.2 \%$ of the mothers relied on their own experience about fever quenching (20).

In the current study, $59.7 \%$ of the mothers referred to a pediatrician for the treatment of febrile children, while in the study by Impicciatore et al. (1998), $90 \%$ of the parents referred to a physician for the treatment of fever (3). In this regard, the results obtained by Oshikoya et al. (2008) indicated that the majority of parents practiced home treatment as the method of choice for fever control (9). High rate of referrals to pediatricians for the treatment of febrile children could be attributed to the excessive concern of parents in this regard.

In some studies, fever has been considered 
a normal immunologic response of the body, enhancing the function of the immune system in some cases, its prompt treatment is unnecessary. Fever leads to the uneasiness of children giving rise to parental concern, which results in the high rate of physician referrals (21). However, in one study, Karimi et al. (2008) claimed that parents should first consult a physician upon the occurrence of fever, and if needed, they are advised to refer the child to the physician (23).

\section{Conclusion}

According to the results of this study, fever phobia was relatively common among mothers, while excessive concern and misconceptions toward fever compelled them to refer the febrile child to a physician repeatedly. This was found to be time-consuming and impose unnecessary costs on families. Therefore, it is recommended that adequate training be provided for mothers, especially those with low education levels, regarding the effective management of fever in children. This could be achieved through changing the attitude and conception of parents regarding the proper control of febrile children.

\section{Conflicts of interest}

The authors have no conflicts of interest.

\section{Authors' contributions}

The authors all made equal contributions to this paper.

\section{Acknowledgments}

Hereby, we extend our gratitude to the Students Research Committee of Sabzevar University of Medical Sciences, healthcare centers of Sabzevar city, and all the mothers for assisting us in this research project.

\section{Reference}

1. Kliegmassn RM, Stanton B, Geme JS, Schor NF, Behrman
RE. Nelson textbook of pediatrics. New York: Elsevier Health Sciences; 2015.

2. Kavehmanesh Z, Amirsalari S, Khalili Matinzadeh Z, Baqheri K. Assessment of mothers' knowledge and attitudes of military families toward management of fever in their child. J Milit Med 2008; 10(1):57-61 (Persian).

3. Impicciatore P, Nannini S, Pandolfini C, Bonati M. Mothers' knowledge of, attitudes toward, and management of fever in preschool children in Italy. Prev Med 1998; 27(2):268-73.

4. Sarrell M, Cohen HA, KahanE. Physicians', nurses', and parents' attitudes to and knowledge about fever in early childhood. Patient Educ Couns 2002; 46(1):61-5.

5. Kathleen O. Pediatric signs \& symptoms. Philadelphia: Llippincott Williams \& Wilkins; 2004.

6. Nelson JD, McCracken GH. The pediatric infectious diseases. Texas: The University of Texas; 2000.

7. Reshadat S, Shakibaei D, Rezaei M, Ghasemi A. Fever management in parents who have children under 5 year. Sci J Hamadan Univ Med Sci 2012; 19(2):28-33 (Persian).

8. Matziou V, Brokalaki H, Kyritsi H, Perdikaris P, Gymnopoulou E, Merkouris A. What Greek mothers know about evaluation and treatment of fever in children: an interview study. Int J Nurs Stud 2008; 45(6):829-36.

9. Oshikoya KA, Senbanjo I. Fever in children: mother's perceptions and their home management. Iran $\mathrm{J}$ Pediatr 2008; 18(3):229-36.

10. Blumenthal I. What parents think of fever? Fam Pract 1998; 15(6):513-8.

11. Sajadi Hazaveh M, Shamsi M. Assessment of mother's behavior in preventing febrile convulsion in their children in Arak City: an application of Health Belief Model. J Jahrom Univ Med Sci 2011; 9(2):34-40 (Persian).

12. al- Eissa YA, al-Zamil FA, al-Sanie AM, al-Salloum AA, al-Tuwaijri $\mathrm{H}$, al-Abdali NM, et al. Home management of fever in children: rational or ritual? Int J Clin Pract 2000; 54(3):138-42.

13. Parmar RC, Sahu DR, Bavdekar SB. Knowledge, attitude and practices of parents of children with febrile convulsion. J Postgrad Med 2001; 47(1):19-23.

14. Mohammadi M. Febrile seizures: four steps algorithmic clinical approach. Iran J Pediatr 2010; 20(1):5-15.

15. Kim D, Lee Y, Lee J, Jeong J, Kim J, Choi M. Perceptions and practices of fever: survey for parents with febrile child visiting pediatric emergency department. Ann Emerg Med 2009; 54(3):S92.

16. Crocetti M, Moghbeli N, Serwint J. Fever phobia revisited: 
have parental misconception about fever changed in 20 years? Pediatrics 2001; 107(6):1241-6.

17. Talebia A, Honarpisheh A, Mohajeri S, Taghddosi M. Surveying the risk factor for first convulsion. Feyz 2003; 13(2):50-7 (Persian).

18. Desnous B, Goujon E, Bellavoine V, Merdariu D, Auvin S. Perceptions of fever and fever management practices in parents of children with Drave syndrome. Epilepsy Behav 2011; 21(4):446-8.

19. Cinar N, Altun I, Altinkaynak S, Walsh A. Turkish parents' management of childhood fever: a cross-sectional survey using the PFMS-TR. Australas Emerg Nurs J 2014; 17(1):3-10.

20. Kilmon CA. Parents' knowledge and practices related to fever management. J Pediatr Health Care 1987; 1(4):173-9.

21. Golestan M, Karbasi SA, Bafgi MS, Behjati M, Mosadegh MM. Comparision of oral acetaminophen with different doses in febrile chidren. Iran J Pediatr 2005; 15(4):373-8.

22. Nouri NM, Rajayi S, Bariri T. Effects of antipyretic of acetaminophen and ibuprofen in children six months to ten years. J Med Hormozgan 2008; 12(1):1-6 (Persian).

23. Karimi A, Fahimzad S, Armin S. Febrile convulsion. Sci J Nezam Pezeshki 2008; 26(2):246-4 (Persian). 